\title{
А.И.Гончаров, Л.И.Шапошникова
}

\section{ОБ ОСОБЕННОСТЯХ МОРФОЛОГИИ ПРЕДСТАВИТЕЛЕЙ САLLOPSYLLA CASPIA ИЗ РАЗЛИЧНЫХ ЧАСТЕЙ ЕЕ АРЕАЛА}

\author{
ФГУЗ «Ставропольский научно-исследовательский противочумный институт»
}

\begin{abstract}
В результате проведенного анализа установлено, что в Китае обитает не Callopsylla caspia fragilis, a 1 или 2 новых (ssp. n.) подвида Cal. caspia. А Cal. уuі является не более, чем подвидом (stat. nov.) Cal. caspia. В Таджикистане, Афганистане и в Пакистане обитают представители нового (1 или 2) подвида Cal. caspia. Указаны особенности самок разных подвидов Cal. caspia.
\end{abstract}

Ключевые слова: новый подвид, ареал, половая клешня, крючок эдеагуса, дифференциальные признаки, синоним.

Callopsylla caspia (Ioff et Argyropulo, 1934) [5] был выделен В.Е.Тифловым по экземплярам, добытым им 26.05.1932 г. в Аксайском ущелье Заилийского Алатау (близ города Алма-Ата) из гнезда «мыши?» (вернее - полевки?), а так же 26.07.1932 и 11.08.1932 гг. из гнезда «Dyromys» (=Dryomys) nitedula angelus (по-видимому, случайный хозяин).

Рисунки и описание этого вида были опубликованы только в 1937 г. [4]. А в 1934 г. в работе И.Г.Иоффа и А.И.Аргиропуло [5] по блохам Армении (т.е. тремя годами ранее) указаны особенности этого вида (без ссылок на В.Е.Тифлова) и поэтому И.Г.Иоффа и А.И.Аргиропуло теперь считают авторами первоописания.

Следует отметить, что у всех самцов, добытых В.Е.Тифловым в Заилийском Алатау, в средней части основания дигитоида имеется небольшой бугорок, как правило, отсутствующий у экземпляров из других мест (кроме одного самца из Болгарии). Вершина горизонтальной ветви девятого стернита острая, несколько изогнута вниз. Кроме того, у трех самцов из Заилийского Алатау, длинная щетинка на заднем крае дигитоида расположена близко к основаниям двух коротких шипиков, а расстояние между двумя длинными щетинками заднего края дигитоида варьирует.

Форма неподвижного отростка половой клешни и расположение оснований ацетабулярных щетинок у всех самцов из Заилийского Алатау разные. Вершина крючка эдеагуса едва изогнута вниз. Особенности дигитоида, горизонтальной ветви девятого стернита и крючка эдеагуса в разных частях ареала (т.е. у разных подвидов) Callopsylla caspia сильно отличаются.

У самки из Заилийского Алатау высота стигмы 8 тергита равна длине церка и ширине резервуара семеприемника. Особенности кавказских особей указаны ранее [5]. Склеротизация муфты копулятивной сумки уже, чем высота резервуара семеприемника.

У самцов из Бардобы (Алайская долина в Киргизии) вершина горизонтальной ветви 9 стернита округлая, а «клюв» крючка эдеагуса прямой и не- много длиннее, чем у Cal.c. caspia. Задне-верхний край дигитоида без очень длинного выступа. Этот самец близок к самцу из Афганистана [6] и к особям из окрестностей озера Искандер-куль (Гиссарский хребет, Таджикистан). У самки из окрестностей озера Искандер-куль стигма 8 тергита менее высокая (гораздо короче церка), а резервуар семеприемника более узкий, чем у Cal. c. caspia.

У самцов из Пакистана (Гилгит; Hazara, DistKaghan Valley) (ранее неправильно определенных как Cal. fragilis ssp. n.), в отличие от самца из Бардобы (ssp. n.), из окрестностей озера Искандер-куль и из Афганистана, задне-верхний край дигитоида заметно более вытянут. Вершина горизонтальной ветви 9 стернита округлая, а задне-нижний выступ на заднем крае дигитоида более смещен вверх. Но «клюв» крючка эдеагуса прямой, и крючок отличается от такового Cal. c. fragilis формой вентрального края.

У самки из Пакистана высота стигмы 8 тергита немного меньше длины церка, а резервуар семеприемника относительно узкий (его высота заметно меньше склеротизации копулятивной сумки). Пакистанских особей, по нашему мнению, целесообразно относить к новому подвиду Cal. caspia ssp. n., а его описание будет дано в отдельном сообщении.

Из Болгарии (Родопы) описан [8] подвид Cal. caspia rhodopeia, близкий к Cal. c. caspia (но опубликован только рисунок половой клешни). У исследованных нами двух самцов из Болгарии форма дигитоида и вершины горизонтальной ветви 9 стернита, расположение оснований ацетабулярных щетинок, длина тела и манубриума половой клешни несколько отличались. Cal. c. rhodopeia помещен [9] в синонимы Cal. caspia, но, в отличие от Cal. c. caspia, у Cal. c. rhodopeia (= ssp. propria), вершина горизонтальной ветви 9 стернита не острая, а соотношение длины тела половой клешни к его ширине (41:37) меньше (у Cal. c. caspia-40:28). У самки Cal. c. rhodopeia стигма 8 тергита гораздо шире высоты резервуара семеприемника и равна ширине склеротизации в узкой (равной высоте стигмы 8 тергита) муфте ко- 
пулятивной сумки.

В 1953 г. опубликовано [3] краткое описание Cal. fragilis, позже помещенного [9] в синонимы Cal. caspia. Но у самцов Cal. c. fragilis вершина узкой горизонтальной ветви 9 стернита широкоокруглая, а задне-нижний край дигитоида расположен более высоко (на уровне основания верхней ацетабулярной щетинки), чем у Cal.c. caspia. Наиболее надежно Cal. c. fragilis (= ssp. propria) отличается от близких подвидов и других видов формой вентрального края крючка эдеагуса (выемка этого края почти широкоокруглая). Форма неподвижного отростка половой клешни и задне-нижнего выступа дигитоида у разных особей (из Бетпакдала и в Карагандинской области) отличаются.

У самки ширина склеротизации в муфте копулятивной сумки равна высоте резервуара семеприемника, а высота стигмы 8 тергита немного короче церка.

На рисунке 469 в сводке по блохам Синьцзяня [10] и на рисунках 1712-1713 в работе по этим паразитам Китая [7] изображены самцы не Cal. c. fragilis (см. форму вершины горизонтальной ветви 9 стернита и вентрального края крючка эдеагуса), a Cal. $c$. caspia или весьма близкого к нему нового подвида (ssp. n.?). Но, в отличие от «типичных» Cal. c. cas$p i a$, у этих самцов задне-нижний выступ дигитоида более сильно (как у Cal. c. fragilis) сдвинут вверх. Возможно, поэтому этих самцов отнесли к Cal. c. fragilis, но крючок эдеагуса у них сильно отличается от такового Cal. c. fragilis.

На рисунке 471 [10] у самки резервуар семеприемника узкий, длинный, а копулятивная сумка очень широкая (более чем вдвое шире высоты семеприемника). Склеротизация копулятивной сумки почти равна ширине придатка семеприемника (у Cal. c. fragilis - вдвое шире его).

У самца из Китая, весьма близкого к Cal. c. caspia и изображенного на рисунке 1707 [7], в отличие от типичных Cal. c. caspia, дорсальный край дигитоида короче длины тела половой клешни, а «клюв» крючка эдеагуса не меньше ширины горизонтальной ветви 9 стернита (у синтипов Cal. c. caspia-меньше). У самки, изображенной на рисунке 1708 [7], стигма 8 тергита невысокая (короче длины церка), а склеротизация в муфте копулятивной сумки, возможно, шире, чем у «типичных» Cal. c. caspia.

Следовательно, для территории Китая нет достаточно убедительных данных о наличии там Cal. c. fragilis, но на этой территории обитают представители Cal. c. caspia и подвида Cal. caspia, близкого (или идентичного) к обнаруженному в Таджикистане и изображенного на рис. 466 в сводке [10], а также на рис. 1707 [7] - еще одного нового подвида.

В 1950 г. З.М.Вовчинская [2] из Баян-Хонгорского аймака Монголии описала Cal. gaiskii (позже помещенный в число подвидов Cal. caspia), у которого субапикальная часть горизонтальной ветви 9 стернита узкая, дорсальный край дигитоида обычно более выпуклый, а задне-нижний выступ дигитоида и верхняя щетинка на его заднем крае расположены гораздо выше, чем у типичных Cal. caspia. Средняя часть дигитоида у Cal. c. gaiskii (= ssp. propria) шире (дорсальный край в 2 раза длиннее середины), чем у Cal.c. fragilis (у последнего это соотношение равно почти 2,5:1), а длинная щетинка на его заднем крае расположена близко к основанию шипиков.

У самки на 7 стерните почти вдвое меньше щетинок, чем у Cal. c. caspia. Высота стигмы 8 тергита равна церку и немного больше высоты резервуара семеприемника и склеротизации в муфте копулятивной сумки.

В 1990 г. [10] опубликовано описание и рисунки Cal. yui и отмечено, что у нового вида дорсальный край дигитоида менее выпуклый (но такие самцы есть и в Тыве), чем у Cal. gaiskii, а задне-нижний выступ у некоторых особей расположен почти на середине его высоты.

У Cal. yui и Cal.c. fragilis рукоятка половой клешни более чем в 2,5 раза длиннее средней части дигитоида, a у Cal. c. gaiskii - менее чем вдвое. Из-за близкого расположения основания верхней длинной щетинки заднего края дигитоида к основанию шипиков, Cal. yui весьма (как и формой горизонтальной ветви 9 стернита и дигитоида) похож на Cal. c. gaiskii. Хотя у Cal. yui вершина крючка эдеагуса более изогнута вниз, а рукоятка половой клешни длиннее (больше дорсального края дигитоида), чем у Cal. c. gaiskii (у которого рукоятка короче или равна дорсальному краю дигитоида), считаем, что Cal. yui является одним из подвидов Cal. caspia (stat. nov.), весьма близким, если не идентичным Cal. c. gaiskii. Изучение дополнительных материалов позволит уточнить систематическое положение особей из Китая, так как в Национальной коллекции блох России, хранящейся в Ставропольском научно-исследовательском противочумном институте, имеются только единичные экземпляры блох из Китая.

\section{СПИСОК ЛИТЕРАТУРЫ}

1. Гончаров А.И. О подвидах Callopsylla caspia (Ioff et Argyropulo, 1934). В кн.: Фауна Ставрополья: Межвуз. сб. науч. тр. Ставрополь, $1995 ; 6: 146-7$.

2. Иофф И.Г., Скалон О.И., Вовчинская 3.М., Дарская Н.Ф., Емельянова Н.Д., Исаева-Гурвичч Э.В. и др. Новые виды блох. Сообщение II. Мед. паразитол. и паразитарн. бол. 1950; 19(3):268-73.

3. Иофф И.Г., Гершкович Н.Л., Загнибородова Е.Н., Лабунеи Н.Ф., Лебедев А.Д., Микулин М.А. и др. Новые виды блох (Suctoria - Aphaniptera). Сообщение III. Мед. паразитол. и паразитарн. бол. 1953; 5:460-5.

4. Тифлов В.Е. К изучению фауны блох (Aphaniptera) восточной части Казахской ССР. В кн.: Тр. Казахского филиала Академии Наук Союза ССР. 1937; 2:189-219

5. Ioff I., Argyropulo A. Die Flohe Armenies. Zeitschrift fur Parasitenkunde. Berlin, 1934; 7(2):138-66.

6. Lewis R.E. Siphonaptera collected during the 1965 Street expedition to Afganistan. Fieldiana Zoology. 1973; 64:161.

7. Liu C. et al. Fauna Sinica. Insecta. Siphonaptera. Beijing : Science press; $1986.1334 \mathrm{~s}$

8. Rosicky B., Daniel M., Cerny V., Mrciak M., Gregor F., Povolny D. Zur Kenntnis der Flohe (Aphaniptera) Bulgariens. Vysledky zoologicke expedice CSAV do Bulgarska (Cast III). Prace Brnenske zakladny Ceskoslovenske Akademie Ved. Sesit 7, spis. 390, rochik XXXI. 1959. S. 321-54.

9. Smit F.G.A.M., Wright A.M. A list of code nambers of species and subspecies of Siphonaptera. Dep. of Entomology British Museum (Natural History). London; 1978. 
10. Yu X., Ye R., Xie X. The fauna of Xinjiang. Xinjiang Peoples Publishing House, Urumqi; 1990. 542 s.

\section{A.I.Goncharov, L.I.Shaposhnikova}

The Particularities of Morphology

of the Callopsylla caspia

\section{Representatives from Different Parts of Its Areal}

Stavropol Research Anti-Plague Institute

The analysis carried out demonstrates that China is inhabited not with Callopsylla caspia fragilis, but with 1 or 2 new (ssp. n.) subspecies of Cal. caspia. Cal. yui was proved to be the subspecies (stat. nov.) of Cal. caspia. In Tadjikistan, Afghanistan and Pakistan representatives of new (1 or 2) subspecies of Cal. caspia reside. Peculiarities of the females of different subspecies of Cal. caspia are presented.

Key words: new subspecies, area, reproductive claw, the aedeagus' hook, differential features, synonym.

\section{Об авторах:}

Гончаров А.И., Шапошникова Л.И. Ставропольский научноисследовательский противочумный институт. 355035, Ставрополь, ул. Советская, 13-15. E-mail: snipchi@mail.stv.ru

Authors:

Goncharov A.I., Shaposhnikova L.I. Stavropol Research AntiPlague Institute. 355035, Stavropol, Sovetskaya St., 13-15. E-mail: snipchi@mail.stv.ru

Поступила 28.08.09. 